\title{
COLLECTIVE PROTECTION EQUIPMENT AND MEASURES IN CONSTRUCTION DURING WORK AT HEIGHT
}

\author{
Maris Ziemelis ${ }^{1}$, Dr.sc.ing./Assist.Prof.; Janis Ievins ${ }^{2}$, Dr.oec./Prof.; \\ Jelena Malahova ${ }^{3}$, Dr.oec./Assoc.Prof. \\ $1,2,3$ Riga Technical University
}

\begin{abstract}
The aim of the paper is to identify in the construction sector problems associated with the work at height arising from incorrect or insufficient planning and use of collective protective equipment, to provide practical proposals for the improvement of collective protection measures at construction sites. Practical suggestions for the improvement of collective protection measures at construction sites are presented in the paper: the system has been developed as a solution of for collective protection means to be foreseen and included in the project report. Practical solutions for collective protection measures are presented. A structural flowchart of the labour protection system at the construction site has been developed in order to ensure the control of the availability and technical condition of collective protection equipment as well as their advance planning and informing of the employees.
\end{abstract}

Key words: labour protection.

JEL code: R19, L89

\section{Introduction}

At workplaces, people spend about one third of their lives. The content of work and the workplace have a positive effect on the employee ensuring the achievement of career goals and economic well-being. At the same time, it greatly affects the state of human health, productivity and motivation. The greatest value of any company is its employee, moreover, healthy and ablebodied to qualitatively carry out the duties assigned to him.

The construction sector is one of the most important economy sectors in the European Union and Latvia looking at the indicators of the finance and the number of employees. It meets people's demand for new housing, office spaces and commercial premises, builds a new infrastructure and improves the existing one.

From the standpoint of labour protection, construction shall be considered as one of the most dangerous sectors since the workers often suffer from work accidents and occupational diseases. This is one of the sectors where work at height is carried out most often. During such work, it is possible to fall from a height into foundation pits and trenches excavated already in the zero-cycle phase, from scaffolds, buildings, work decks, mobile towers, work platforms, temporary ladders, stairs, roofs where different types of work are performed, through unfenced and uncovered openings of roofs or interfloor constructions etc. (INSPECTA, 2008). Work at a height is considered one of the most dangerous jobs - every year there are many accidents caused by falling from a height. Almost always these accidents have serious consequences, often lethal.

The employer's duty is to provide a safe working environment for its employees - including everything necessary to work safely at height (Riga Stradins University, 2011). Based on the results of the work environment risk assessment, the employer needs to establish measures to prevent falling from heights:

1) eliminate the hazard, i.e. the very work at height (which is practically impossible in the construction industry);

2) ensure an adequate protection against falling from height:

- use of collective protection equipment (scaffolds, protective fencing, protective nets etc.);

- use of personal protection equipment if use of collective protection equipment is not possible;

- training of employees who carry out work at height (Riga Stradins University, 2013). 
As a key measure, it should be noted a well-thought-out safe work programme to protect against falling from height where the risks are first reduced by technical and organizational measures. Application of collective labour protection measures is primary compared to personal protective equipment (Labour Protection Law, 2001) since they protect a larger number of employees and their safe use is not significantly dependent on the employee himself.

Since technical solutions of the construction projects are different and situation at the construction site is constantly changing due to the interaction and development of different work stages, it is necessary to identify and eliminate the risks associated with the problems of planning and use of collective protection equipment and their compliance with the regulatory enactments. Improving the collective protection solutions at construction sites will reduce the impact of hazardous work environment risk factors and the probability of accidents.

\section{Analysis of accidents in construction sector}

Construction is considered one of the most dangerous sectors since it is featured by a high accident rate at a workplace. According to Eurostat, about 4.200 people die every year in workrelated accidents in the European Union, of which about 1.000 are employed in the construction industry, accounting for 24 \% (European Commission, 2016). In Latvia, construction workers more than average suffer from work accidents and occupational diseases.

According to statistical data of the State Labour Inspectorate accident, within the period 2008 to 2014 there were 10.669 accidents at work, of which 1.074 in construction sector, i.e. average $10 \%$ of the total number (Table 1 ).

Table 1.

Distribution of workers suffered in accidents by industries in Latvia within 2008 to 2014

\begin{tabular}{|c|c|c|c|c|c|c|c|c|}
\hline & 2008 & 2009 & 2010 & 2011 & 2012 & 2013 & 2014 & Total \\
\hline \multicolumn{9}{|c|}{ Accidents at workplace } \\
\hline Construction sector & 234 & 120 & 102 & 138 & 174 & 157 & 149 & 1.074 \\
\hline$\%$ & 13 & 10 & 8 & 10 & 11 & 9 & 8 & $\sim 10$ \\
\hline Total in all sectors & 1.781 & 1.203 & 1.232 & 1.397 & 1.545 & 1.748 & 1.763 & 10.669 \\
\hline \multicolumn{9}{|c|}{ Grave accidents at workplace } \\
\hline Construction sector & 74 & 37 & 27 & 30 & 41 & 45 & 42 & 296 \\
\hline$\%$ & 28 & 21 & 15 & 15 & 19 & 20 & 220 & $\sim 20$ \\
\hline Total in all sectors & 265 & 175 & 175 & 196 & 219 & 230 & 213 & 1.473 \\
\hline \multicolumn{9}{|c|}{ Lethal accidents at workplace } \\
\hline Construction sector & 12 & 7 & 5 & 10 & 11 & 3 & 5 & 53 \\
\hline$\%$ & 28 & 22 & 20 & 29 & 31 & 10 & 12 & $\sim 22$ \\
\hline Total in all sectors & 43 & 32 & 25 & 34 & 35 & 31 & 41 & 241 \\
\hline
\end{tabular}

Source: State Labour Inspectorate, 2013 - 2015

According to data of the State Labour Inspectorate, one of the main traumatic factors in fatal and severe accidents is falling from height and impact caused by object falling from height. Statistical data for the period 2008 to 2014 are given in Table 2. 
Table 2.

Distribution of workers suffered in accidents by traumatic factors within 2008 to 2014

\begin{tabular}{|c|c|c|c|c|c|c|c|c|}
\hline & 2008 & 2009 & 2010 & 2011 & 2012 & 2013 & 2014 & Total \\
\hline \multicolumn{9}{|c|}{ Number of workers suffered in accidents at workplace } \\
\hline Falling from height & 523 & 411 & 405 & 425 & 517 & 543 & 494 & 3.318 \\
\hline$\%$ & 29 & 34 & 33 & 33 & 33,5 & 31 & 28 & 31 \\
\hline By falling object & 173 & 83 & 128 & 142 & 139 & 156 & 191 & 1.012 \\
\hline$\%$ & 10 & 7 & 10 & 10 & 9 & 9 & 11 & 9,5 \\
\hline $\begin{array}{l}\text { Total number of } \\
\text { accidents }\end{array}$ & 1.781 & 1.203 & 1.232 & 1.397 & 1.545 & 1.748 & 1.763 & 10.669 \\
\hline \multicolumn{9}{|c|}{ Grave accidents at workplace } \\
\hline Falling from height & 128 & 84 & 85 & 88 & 119 & 118 & 108 & 730 \\
\hline$\%$ & 48 & 48 & 49 & 45 & 54 & 51 & 51 & 50 \\
\hline By falling object & 27 & 16 & 14 & 26 & 23 & 26 & 26 & 158 \\
\hline$\%$ & 10 & 9 & 8 & 13 & 11 & 11 & 12 & 11 \\
\hline $\begin{array}{l}\text { Total number of } \\
\text { accidents }\end{array}$ & 265 & 175 & 175 & 196 & 219 & 230 & 213 & 1.473 \\
\hline \multicolumn{9}{|c|}{ Lethal accidents at workplace } \\
\hline Falling from height & 12 & 2 & 3 & 8 & 6 & 6 & 4 & 41 \\
\hline$\%$ & 28 & 6 & 12 & 24 & 17 & 19 & 10 & 17 \\
\hline By falling object & 5 & 5 & 8 & 7 & 6 & 7 & 5 & 43 \\
\hline$\%$ & 12 & 16 & 32 & 21 & 17 & 23 & 12 & 18 \\
\hline $\begin{array}{l}\text { Total number of } \\
\text { accidents }\end{array}$ & 43 & 32 & 25 & 34 & 35 & 31 & 41 & 241 \\
\hline
\end{tabular}

Source: State Labour Inspectorate, 2013 - 2015

The most frequent causes of grave and lethal accidents are failure to comply with occupational safety regulations or instructions ( $27 \%$ ), unsatisfactory instruction and training of employees $(14 \%)$, and insufficient attention (12\%). Analysing these causes of accidents, it can be concluded that most of the grave and lethal accidents can be prevented by organizational measures without the need of large financial investments.

Problems with a formal approach and lack of training of employees are also confirmed by statistics on the working life of accidents victims: $2 / 3$ of them had a short-term length of employment (up to 3 years) (State Labour Inspectorate, 2015).

\section{Integration of collective protection measures in the construction design}

To ensure a safe working environment at the construction site when working at height, it is necessary to plan the provision of collective protection equipment for a new construction project already during the design preparation stage. It must be ensured that issues of safety and collective protection are integrated into the construction design. Hence, well-thought-out decisions for safe and efficient work shall be developed. Also, the amount of work to be carried out using safety belts should be minimized when use of collective protection equipment is not possible.

As confirmed by the analysis of the construction sites survey, at present time the collective work protection equipment is being overlooked at construction sites, often the equipment is damaged or completely removed, causing the risk of falling for the workers.

One of the main reasons why employees are not paying attention to the state and availability of collective protection equipment is a rapid pace of work and tight work schedules. It is therefore necessary already in the construction design to envisage the technologically effective systems of 
collective protection equipment, which do not extend the production process schedule while qualitatively performing their functions.

\subsection{Implementation of integration process}

In order to be able integrate in the construction design or in the project report the solutions for collective protection equipment during the performance of construction work, it is necessary to review the construction process flowchart (Figure 1) prepared up in accordance with the Construction Law. Timely planning and ensuring the participation of a labour protection specialist at the design stage of the construction allow including well-considered labour protection solutions in the construction design.

The contractor himself is also the general contractor at the same time. Looking at Figure 1, it can be seen that the Labour Protection Coordinator and the responsible foreman must participate in the fulfilment of the design conditions and the corresponding note in the building permit. Therefore, in order to integrate the collective protection measures into the final design, it is necessary to involve the labour protection specialists and the responsible foreman already at the time of the design meetings when the final design is being developed and its parts are mutually coordinated. 


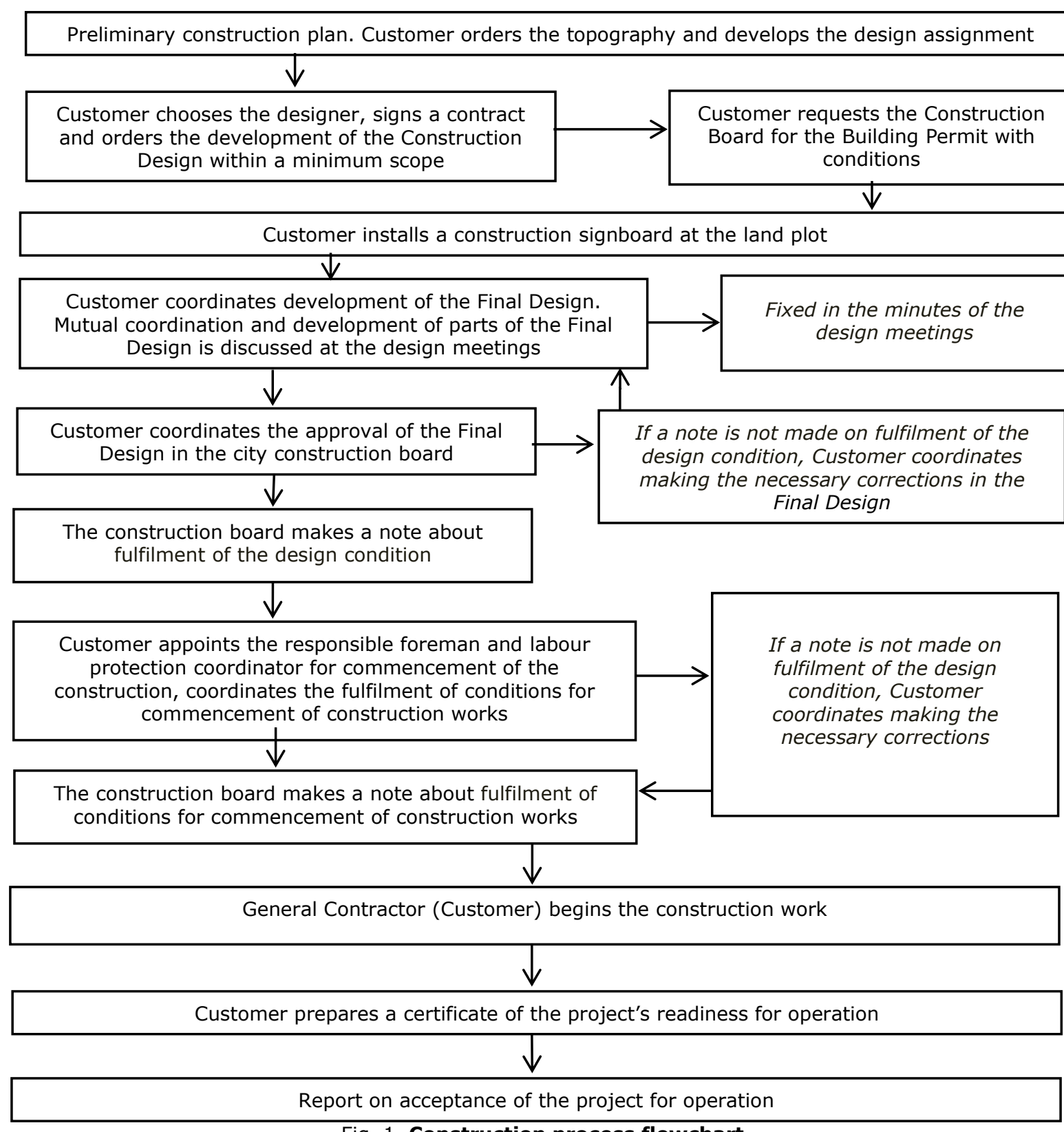

Fig. 1. Construction process flowchart

A solution when the labour protection specialist is involved in design meetings can be used to solve and improve also other occupational safety issues in the construction process. However, when it comes to the inclusion of collective protection measures in the final design, the following persons will be required:

1) labour protection specialist who provides information regarding the necessary labour protection solutions as well as the requirements of regulatory enactments;

2) the designer of construction structure who provides information on new, unfamiliar materials and technologies, points to the points of complicated units; includes the collective labour protection solutions in the final design; indicates possible technical solutions that can be implemented as permanent also during operation of the building;

3) responsible foreman who provides information on the organization of necessary work and its performance phases at the construction site. According to the Cabinet of Ministers Regulation of 19 August 2014 No.500 "General construction regulations", the responsible foreman will be in charge of occupational safety and health at the construction site; 
4) the labour protection coordinator in the design drafting phase, who advises, notes the constructively complicated stages of the construction work, develops the labour protection plan. If the project construction is complicated and more building contractors will work at the construction site, the construction promoter (the customer) shall be obliged to assign the labour protection coordinator in accordance with the Cabinet of Ministers Regulation No.92 of 25 February 2003 "Requirements for labour protection during construction work" and the Cabinet of Ministers Regulation No.500 of 19 August 2014 "General construction regulations".

When the customer has entered into an agreement with the designer, has received a conditional building permit and installed a construction signboard on the land plot, he shall also involve the labour protection specialist and the responsible foreman in the development of the final design, and shall appoint the labour protection coordinator for the project planning stage. Thus, the competent persons can go into details and participate in the development of the final design, plan the reliable and efficient solutions for the construction process.

At the design meetings, solutions are being developed for the inclusion of collective protection equipment in the structures of the construction project. The meetings are recorded in order to avoid subsequent disagreements. The designer gradually includes the labour protection solutions in the construction project (Figure 2). In turn, the labour protection coordinator develops the work protection plan to be included as part of the work organization plan and submits it to the designer.

After development of the final design, it is checked in relation to the labour protection issues by the labour protection specialist, the responsible foreman and the labour protection coordinator. If all necessary measures are included in the design, it will be submitted further to the customer for approval so that the design could be subsequently coordinated with the city construction board.

The flowchart shown in Figure 2 will allow to include the well-thought-out collective protection solutions in the final design. It will facilitate and improve the labour protection on complicated stages of construction. It should be noted that it is not enough to simply include the collective protection solutions in the construction project. It is necessary to carry out their supervision throughout the construction process in order not to make changes for the reduction of construction costs in relation to the labour protection solutions, as well as to ensure their technical condition and availability in work performance. 


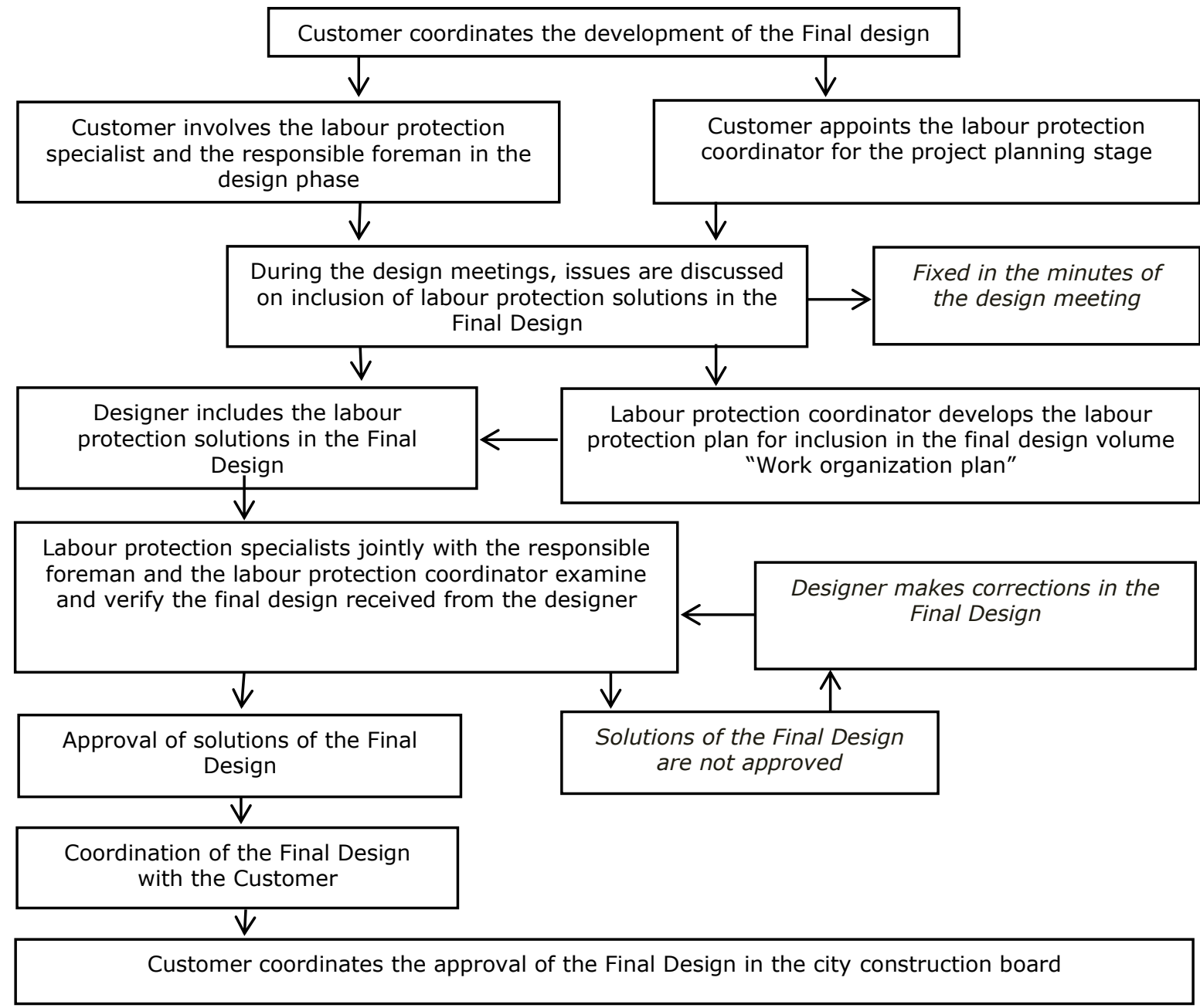

Fig. 2. Flowchart of protection equipment integration in the construction design

\subsection{Collective protection measures in projects with structures of monolithic reinforced concrete}

When carrying out work where the building frame is made of monolithic reinforced concrete structures, there is a high risk of falling. The construction process requires carrying out the reinforcement, forming and concreting works of a complicated technology. Work is often done in large and unconstrained areas, the work processes are permanently changing, safety devices are often removed and relocated, safety belts are not always used when necessary. Consequently, the labour protection measures must be carefully planned and monitored.

In practice, there are often cases when a safety device against falling is installed but it creates additional risks for workers at the construction site. Therefore, when designing the collective protection solutions, care should be taken not to create additional risks for employees at the construction site.

\section{Solutions for the integration of collective defence equipment into reinforced concrete structures}

One of the most effective and convenient rail mounting solutions is to incorporate the railing fastenings in the ceiling and wall constructions. Metal or plastic pipeline (approximately $15-25 \mathrm{~cm}$ long) is placed and secured to the reinforcement frame and then concreted, thus creating a solid foundation for railing structures. The railing structures are made of a smaller diameter pipe or a square tube subsequently placed in the foundation. This solution allows the rails to be installed and disassembled much quicker and practically in any required location. 
The handrail design itself is developed with the corresponding mounting points for the foot rail, middle rail and top rail at heights specified in regulatory enactments. It facilitates the assembly of wood as well as the correct height control during labour safety tours. The railing structures are mobile, so they can also be used in other projects. This solution is simple, economical and durable.

A faster, safer and at the same time more expensive solution is to use the industrially manufactured protection railing guard. Fastenings of respective diameter must be provided in the final design for these rails that, like the metal pipes, must be fastened to the metal frame and concreted in the supporting structure.

In construction of residential buildings, the exterior walls of the reinforced concrete frame are often masoned. To perform these works, it is necessary to remove the protection guards. It means that employees engaged in these works will have to wear safe belts and it will be necessary to constructively arrange their fastening spots - the anchor points. One of the solutions is to imbed in concrete two reinforcement bars in the columns $10-20 \mathrm{~cm}$ below the slab, but later they will need to be cut off and, if there are many openings, then the process will very labour-consuming. Another solution is to provide for the anchorage points in the reinforced concrete columns, at which upper part a tie can be wrapped up, fastened and then connected with ropes for the anchoring of personal protection equipment.

Although the anchor points are provided for strengthening of the safety belts, an additional protection needs to be provided with use of catch nets. It will provide both the additional protection in case of falling worker as well as against falling materials and other objects. The final design should provide for the fastening of these systems in the structures of the reinforced concrete frame.

If it is necessary to carry out the frame erection works within a wide area, the mounting points (cone-shaped pipes) should be provided in the reinforced concrete columns or walls for a separately installable ALSINA system structure that is intended for the protection of workers against falling with personal protection equipment added.

This system can be used in cases when it is necessary to install the formworks and the collective protection equipment (railings and safety nets). The ALSINA system has been manufactured and tested in accordance with the requirements of DIN EN 795 and ANSI Z359.6 / CSA Z259.16. This protection system eliminates accidents in risky situations besides unprotected edges and at big heights. The system includes a retractable device with a blocker, which automatically locks when an acceleration suddenly occurs. Thus, an accidental fall can be stopped and the injury risk can be reduced (Encofrados J.Alsina, S.A. - Central, 2016).

Before performance of work, the system must be tested. The work life of the equipment is average 5 to 10 years. The protective equipment must be in a proper condition, therefore the tests must be carried out in accordance with the requirements specified by the manufacturer (Encofrados J.Alsina, S.A. - Central, 2016).

\subsection{Collective protection measures in projects with structures of prefabricated reinforced concrete panels}

Construction of the building frame from prefabricated reinforced concrete structures is a relatively fast and technologically arranged process where the frame structures are delivered ready to the construction site. In order the necessary labour protection solutions would be implemented industrially, they must be initially provided for in the drawings of the final design. 
The construction design may provide for the railing fastening in the facade parts of external reinforced concrete panel walls. These anchors are permanent, they are later covered when warming the building with stone wool insulation.

Since the bottom edge of the window opening is lower than one meter, it requires the installation of a railing to protect against falling. The final design can provide that the reinforced concrete wall panel structures are delivered with wooden plank frames incorporate in windows. These are permanent elements in the frame of the building and later they will covered with heat insulation. One or two railings for protection against falling are mounted in these frames onsite at the construction site (in the materials storage), they are removed when it is necessary to perform window assembly works. Reinforced concrete wall structures are later installed with already mounted railing in the window openings, thus eliminating the risk that the rails should be installed at height using personal protective equipment.

A film is mounted at these wooden frames of window openings to protect from draught in and maintain heat in the building. The film is installed on an already assembled reinforced concrete structure. Consequently, such collective protection solution is capable to eliminate more risks.

\subsection{Incorporation of anchor points in the final design}

Anchor point is a stationary or temporary safety point, to which safety means are fastened, including ropes and slings, and which in combination with personal protection equipment is designed to prevent an employee from entering the risk area of falling or, when the work is carried out in an area where the risk of falling exists, to ensure that the fall will be stopped (Labour protection requirements..., 2014).

Inadequate anchor points in practice is often used for performance of work. In facade finishing, ropes are often used to access the workplace and carry out the work. The safety system consists of two ropes, which are fixed at one point. According to Cabinet Regulation No.143 of 18 March 2014 "Labour protection requirements when working at height", they must be individually fixed at stationary anchor points. Also, the anchor point itself where the rope is fixed is not compliant with the requirements of the standards LVS EN 795 or LVS EN 517.

According to the Cabinet of Ministers Regulation No.143 "Labour protection requirements when working at height" of 18 March 2014, two ropes are used but their protection against rubbing against rough surfaces is not provided.

It is important that the construction design preliminarily provided for anchor points meeting the requirements of LVS EN 795 or LVS EN 517 standards. Integrating such proven and certified systems of solutions will allow employees to perform their work safely.

\section{Solutions for integration of anchor points into the final design}

When constructing residential buildings, work often needs to be done on balconies when protective guard is not yet installed or has to be removed, for example, to accept the materials. In this case, workers should wear safety belts but they need to be fastened. The designer must provide for locations of anchor points where the worker can attach his own personal equipment to carry out the work. The construction project shall include incorporation of mobile anchors into the balcony surface structures.

It is efficient and economical to use mobile and reusable anchor points that are incorporated into reinforced concrete structures. Thus, such anchorages can also be used in other construction 
projects. These anchor points meet the requirements of standard LVS EN 795 Class B, their installation and inspection must be carried out according to the manufacturer's recommendations (Skydda, 2016).

In Finland, special horizontal safety lines are often used, which are intended to strengthen the safety straps of the worker when the work is carried out at open and unprotected edges. Such horizontal safety lines should be fixed to a beam of type I, reinforced concrete columns or roof. Depending on the chosen mounting location, the type of the safety line design is also chosen. It is important to choose a system that is manufactured and tested to meet the requirements of the standards, and only thereafter it can be fastened against the intended structure. Layouts of anchor structures and safety system must be provided for in the final design.

The final design must provide for remaining and permanent anchor points incorporated in the roof structures. Thus, the work safety will be improved not only during the construction but also during the operation and maintenance of the building. According to the requirements of LVS EN 795 or LVS EN 517, it is possible to select respective anchor points for structures of different roof slope and covering.

The designer of the building structures section must anticipate all necessary anchor points, determine the dimensions and incorporate them in the design plans so as to ensure the safety of builders.

\section{Management of construction project labour protection system}

Based on the performed studies - data on causes of accidents at workplace, analysis of the results of surveys of employees at construction sites and information on collective protection equipment obtained during inspection of construction sites, it can be concluded that it is necessary to arrange the organizational structure of the construction site labour protection in relation to the training and informing of employees, as well as the control over fulfilment of requirements of labour protection, including collective protection.

\subsection{Organizational structure of labour protection system at the construction site}

Each day workers at the construction site have a rapid pace of work and tight work deadlines, various construction works are interacting and more contractors are simultaneously employed. Priority at construction sites is given to performance of work while labour protection requirements are neglected, they are often forgotten. Insufficient attention is paid to the planning of labour protection measures prior to the commencement of construction work; often urgent solutions are sought directly during the construction work.

Also, workers employed at construction sites most often formally are acquainted with the labour protection plan. Information therein delivered for the employees is only partly useful. The employees are undertrained and insufficiently informed.

Therefore, in order to arrange the organizational structure of the construction site labour protection system, we offer the following stages of activities:

- thorough planning of safety measures prior to commencement of work;

- training and informing of employees;

- control over observance of labour protection requirements. 


\subsection{Planning of labour protection measures}

Safety solutions need to be planned before starting the construction work; safe working methods must be provided in all phases and periods of construction.

In accordance with the Cabinet of Ministers Regulation No.92 of 25 February 2003 "Labour protection requirements for construction work", the customer must appoint the labour protection coordinator for the project fulfilment phase, i.e. for the construction phase. This appointment must be submitted to the city construction board as one of the conditions for obtaining a note in the building permit on execution of requirements for commencement of construction works.

The labour protection specialist needs to be appointed as the labour protection coordinator for the project fulfilment phase, thus the problems of labour protection at the construction site will be solved by an individual competent person, as well as supervision will be retained over realization of collective protection means integrated in the construction project. In practice, a person with a certificate of construction practice in the management and supervision of construction works and a basic level of knowledge in labour protection is usually appointed as a labour protection coordinator. This person has other official duties at the construction site; therefore, a superficial attention is paid to the supervision of labour protection requirements.

Prior to the commencement of construction work, the labour protection coordinator shall for the project fulfilment phase carry out an examination of the labour protection plan and, if necessary, make corrections thereof.

\section{Incorporation of labour safety requirements in the organized procurements}

The project manager organizes a price survey for each type of work and chooses an appropriate contractor. Within the framework of the tender, a price request is sent to different companies along with the final design documentation, quality requirements, deadlines for execution and the most important contractual conditions.

According to the authors, the documentation of the procurement request must also be accompanied by the necessary labour protection requirements for the type of work involved. Consequently, the contractors will be able to plan not only the work to be done in a timely manner, but also safe working methods, including the detailed costs of labour protection in their estimates. The labour protection coordinator for the project implementation phase shall define the labour protection requirements for each type of work in the procurement tender and shall include them in the price request form.

Upon receipt of the bids, the project manager together with the labour protection coordinator and the responsible foreman shall choose the contractor to conclude the contract. The contract is accompanied by labour protection requirements with the WS Barometer assessment conditions as well as by rules and regulations of the construction site with the specified penalties for violations of labour protection.

\section{Preparation of the employer's labour protection plan}

Prior to commencement of works, the project manager, labour protection coordinator and responsible foreman shall organize a contractor's project start-up meeting, in which together with the responsible person of the subcontractors shall discuss complicated and dangerous work phases, introduce to the site's labour protection plan and jointly develop the contractor's labour protection plan for the type of work to be carried out. The meetings shall be recorded. 
In the labour protection plans, it is necessary to provide the following information regarding the collective protection equipment:

- technical systems and supporting equipment for each type of work;

- detailed design for formwork, if any;

- scaffolding, footways and other safe working platforms to be used;

- safe anchor points for safety belts (mobile anchor points, safety lines);

- plans for protecting fences and protective covers, indicating the amount of fencing to be installed, the amount of wood and plywood needed, and the possibilities for turnover of the materials (if individual buildings have the same layout).

If the necessary information is included in other construction documents or in drawings of the construction design, then the labour protection plan may contain only indications of the place where the information can be found.

Labour protection methods need to be planned so as to minimize the amount of work carried out using the safety belts.

\subsection{Training and awareness of employees}

Before the work is started, the labour protection coordinator shall train and instruct the contractor's workers. At the end of the training, employees of the construction site shall pass a test on labour protection issues included in the training. If all test answers are correct, the general contractor shall issue a labour protection card and a pass to the site (of business card format).

The issued safety cards are registered in a special register and valid for one year. In turn, the validity of the site passes is specified until completion of the works but not more than one year. If works at the construction site are carried out for more than one year, the contractors receive retraining and complete a knowledge test. After the test is completed, new labour protection cards and site passes will be issued. At the entrance to the construction site, the security guard shall check the passes and their validity. The labour protection coordinator, following the register of issued labour protection cards, can plan the necessary training.

Labour protection cards must be issued not only to the contractor's employees but also to the employees of the general contractor. Prior to the start of work, the main contractor's staff is being trained, after which they take a test to receive the safety card and the site pass. Thus, knowledge of labour protection requirements will be ensured also at the level of management of the construction site.

\subsection{Control over observance of labour protection measures}

Since in construction there are different work phases and processes interacting with each other, and the work at the construction site is carried out by workers of several enterprises simultaneously, a sufficient control over technical condition of the collective protection equipment is not ensured. It is therefore necessary to regularly check the availability and adequacy of collective defence equipment on a daily basis.

As one of the work duties, instruct the assistant foreman to carry out a daily inspection of the condition of collective protection equipment. The established situation must be fixed. In case of non-compliance, the assistant foreman shall inform the labour protection coordinator and the responsible foreman and shall immediately organize the restoration and repair of collective protection equipment or shall bar the approach to the hazardous place. 
To carry out control over labour protection at the construction site, the labour protection coordinator once a week shall conduct labour protection walkdowns, shall fix the established situation in the WS Barometer observation form and shall determine the overall safety level of the construction site.

It is important at the construction sites to carry out weekly WS Barometer walkdowns, and it is equally important for the general contractor to share with the contractors the established labour protection situation at the construction site. Therefore, the obtained results should be discussed during weekly project meetings while the labour protection coordinator must point to the violations and preventive measures taken.

Since disagreements often appear in the construction, all labour protection violations must be formulated in writing, drawing up a report on occupational safety violations with photo fixations. Such violation report must be drawn up immediately, setting the deadline for eliminating noncompliances and submitting it to the responsible contractor. The elimination of labour protection violations within the specified time limits is controlled by the assistant foreman and the responsible foreman, informing the labour protection coordinator accordingly. If dangerous violations occur repeatedly, then the work must be immediately suspended in accordance with provisions of the contract. Works at the site can only be resumed once the hazard has been eliminated.

\section{Conclusions, proposals, recommendations}

In order to develop well-thought-out solutions for safe and efficient work performance at the construction site, as well as to reduce the amount of work to be carried out using safety belts when use of collective protection equipment is not possible, it is necessary to start planning of labour protection requirements for the construction process already in the design phase.

In order to ensure a safe work environment at the construction site when working at height, it is recommended to plan the provision of collective protection equipment for the new building already in the project preparation phase (development of the construction project) and to take the following measures:

1) ensure that issues of occupational safety and collective protection equipment are integrated in the construction project (for a particular project, taking into account the specifics of the construction (for the construction of a monolithic reinforced concrete frame or panel building frame, to provide respective collective protection measures, such as railing mounting places and anchor points);

2) to develop sound labour protection plans, providing for safe working methods in all phases of work, to include technical systems and supporting equipment for respective work phases, pay a special attention to formwork and formwork removal (to develop detailed plans), provide anchor points for hooking of safety belts (for example, ALSINA system, safety lines or mobile anchorage points for carcass construction work before installation of protective guard), include a safe access to the work platforms. The labour protection plan shall also include the detailed drawings with collective protection measures, indicating the number of risk areas, the required amount of wood and plywood for protective guards and hoods of openings, the possibilities of materials circulation for other projects.

During the project implementation phase, the supervision and control over observance of labour protection requirements, including collective protection requirements, should be ensured, as well as should make sure that all employees at the construction site are instructed, trained and familiar 
with labour protection requirements. In the project implementation phase (the construction board has given approval for the fulfilment of conditions for commencement of construction works), it is recommended to take the following measures:

1) To develop a summary of labour protection requirements by types of work to be enclosed with the price request documentation when organizing the construction work procurements. Thus, the contractor will become familiar with the labour protection requirements prior to conclusion of the contract. Labour protection requirements must be added to the contract;

4) Prior to commencement of works, the general contractor together with the contractor shall develop the labour protection plan for individual type of work and shall discusse hazardous work phases;

5) Prior to commencement of works at the construction site, the employees of both the general contractor and the contractor must be trained, given an additional instruction, familiarized with the labour protection plan and requirements for collective protection equipment. After training, the labour protection coordinator should arrange a test of knowledge. The site passes and labour protection training certificates are issued to employees who are familiar with labour protection requirements at the construction site. Only then can the construction work be started;

6) Availability and technical condition of collective protection equipment must be checked on a daily basis;

7) It is recommended to use the Finnish WS Barometer system for the assessment of condition of collective protection equipment at the construction site, which has been supplemented by the author with evaluation criteria for ropes, fastenings and anchor points in accordance with Latvia regulatory enactments;

8) During the project meetings, employees of the construction site must be informed about the established discrepancies as well as good practice examples.

\section{Bibliography}

1. Encofrados J.Alsina, S.A. - Central (2016). ALSIPERCHA Fall Arrest System [online]. Barcelona, Spain: Alsina Formwork Solutions, [viewed 25 October 2017]. Available from: http://www.alsipercha.com/en/alsipercha/ alsipercha-construction/

2. European Commission (2016) [online]. Eurostat. European Statistics [viewed 26 October 2017]. Available from: http://ec.europa.eu/eurostat

3. General Construction Regulations (2014) [online]. Republic of Latvia Cabinet Regulation No.500 Adopted 19 August 2014, [viewed 25 October 2017]. Available from: https://likumi./v/doc.php?id=269069

4. INSPECTA (2008). Ocupational safety, working at heights. Labour protection information - explanatory material. Riga: State Labour Inspectorate. 16 p.

5. Labour Protection Law (2001), [online]. Republic of Latvia, Saeima adopted 20 June 2001 [viewed 25 October 2017]. Available from: https://likumi.Iv/ta/en/id/26020-labour-protection-law

6. Labour protection requirements for construction work (2003) [online]. Republic of Latvia Cabinet Regulation No.92 Adopted 25 February 2003, [viewed 25 October 2017]. Available from:

https://likumi.Iv/ta/en/id/71958-labour-protection-requirements-in-performing-construction-work

7. Labour protection requirements when working at height (2014) [online]. Republic of Latvia Cabinet Regulation No.143 Adopted 18 March 2014, [viewed 25 October 2017]. Available from: https://likumi.lv/doc.php?id=265121

8. Riga Stradins University (2011). A memo to employees who work at a height. Riga: Riga Stradins University Institute for Occupational safety and environmental health. $18 \mathrm{p}$.

9. Riga Stradins University (2013). Labor protection practice standard for the construction industry. Riga: Riga Stradins University Institute for Occupational safety and environmental health. 158 p.

10. Skydda (2016). Fall Protection [online]. Sweden: Skydda [viewed 25 April 2017]. Available from: http://www.skydda.com/en/fall-protection/anchorage/wc785462 p141114 
11. State Labour Inspectorate (2013). State Labour Inspectorate in 2013, Annex 1 Operational Report [online]. Riga: State Labour Inspectorate [viewed 16 October 2017]. Available from: http://www.vdi.gov.lv/lv/parmums/parskati/

12. State Labour Inspectorate (2014). State Labour Inspectorate in 2014, Annex 1 Operational Report [online]. Riga: State Labour Inspectorate [viewed 16 October 2017]. Available from: http://www.vdi.gov.Iv/lv/parmums/parskati./

13. State Labour Inspectorate (2015). State Labour Inspectorate in 2015, Annex 1 Operational Report [online]. Riga: State Labour Inspectorate [viewed 16 October 2017]. Available from: http://www.vdi.gov.Iv/lv/parmums/parskati/ 